\title{
Pharmacogenomics and pharmacoproteomics in the evaluation and management of short stature
}

\author{
Ron G Rosenfeld \\ Lucile Packard Foundation for Children's Health, Stanford University, Oregon Health and Science University, 400 Hamilton Avenue, Suite 340, Palo Alto, \\ California 94301, USA \\ (Correspondence should be addressed to R G Rosenfeld; Email: ron.rosenfeld@lpfch.org)
}

\begin{abstract}
It has long been recognized that growth failure encompasses a diverse spectrum of underlying pathophysiological processes, a characteristic that has significantly impacted both the diagnosis and management of growth disorders. This problem is exacerbated by inherent difficulty in distinguishing the borders between the 'normal range' for stature and defined abnormal growth. Evaluation of GH secretion has proven problematic, both diagnostically and prognostically, except in cases of unequivocal GH deficiency. Measurement of serum concentrations of IGF-I, IGFBP-3, and ALS have proven useful in the assessment of GH responsiveness and have contributed to the concept of primary and secondary 'IGF deficiency'. Nevertheless, there is great need for biochemical and/or molecular biomarkers that could: i) predict short- and long-term responsiveness to various therapeutic modalities, such as GH and IGF-I, and ii) predict potential risk for adverse effects of therapy. Candidate proteins and genes identified to date, and worthy of further evaluation, include IGF-I, IGF-I receptor, GH receptor and its variants (such as exon 3-deleted GHR), STAT5b and short stature homeobox. Proteomic analysis of serum samples pre- and post-treatment and correlation with clinical responsiveness should provide additional candidate biomarkers. Molecular studies to consider include: i) sequencing and mutation analysis of known genetic components of the GH-IGF axis; ii) evaluation of single nucleotide polymorphisms of candidate genes; and iii) identification of new candidate genes. It is proposed that the major target population to study is that of children currently labeled as idiopathic short stature (ISS). These children can be divided into those with: i) primary IGFD, where the focus should be on genes related to GHR, GHR signaling, and IGF-I gene expression, or ii) no IGFD (i.e. "true ISS'), where the focus should be on genes related to IGFR, IGF signaling and epiphyseal growth.
\end{abstract}

European Journal of Endocrinology 157 S27-S31

From a historical perspective, the evaluation and management of children with short stature has been dictated by the availability of growth hormone (GH) as a therapeutic agent. Despite the well-known limitations of GH stimulation tests, they have constituted the focal point of diagnostic evaluations of short children for over 40 years and have regulated access to growthpromoting therapy to a great extent (1).

Perhaps, more importantly, measurements of serum GH concentrations have served to rather arbitrarily divide children with proportionate short stature into categories of 'disease' versus 'normal variants'. Such fractionation ignores the fact that stature, like so many physiological variables, more or less follows a Gaussian distribution (2), and that the dividing line between 'pathology' and 'normal' is not always easy to distinguish. In retrospect,

This paper was presented at the Ipsen symposium, 'The evolving biology of growth and metabolism', Lisbon, Portugal, 16-18 March 2007. Ipsen has supported the publication of these proceedings. it seems incredibly naïve for us to have ever believed that a biological process as complex as human stature, with its different tempos of fetal, infant, childhood, prepubertal and pubertal growth, could ever be explained by one or two hormones.

Several factors have served to require that we reconsider our approach to the evaluation and management of children with short stature: i) an enhanced understanding of the physiology of the GH-insulin-like growth factor (IGF) axis and, in particular, the realization of the critical role of the IGF system in both intrauterine and postnatal growth (3); ii) the development of methodologies for high-throughput discovery and assays of both genomic and proteomic biomarkers; and iii) the availability of new therapies, such as IGF-I, for the management of children with growth failure. These developments should force us to entertain the following questions

1) How do we define 'short stature?'

2) How do we explain short stature? 
3) How do we define responsiveness to growthpromoting therapy?

4) How do we predict responsiveness to growthpromoting therapy?

\section{How do we define 'short stature?'}

An honest evaluation of the management of short stature over the last 50 years would inevitably lead to the conclusion that rather than diagnosis dictating therapy, the availability of therapy (namely $\mathrm{GH}$ ) dictated diagnosis. Because approval of GH therapy was, for many years, limited to children with diagnosis of $\mathrm{GH}$ deficiency (GHD), GH stimulation tests were abused in efforts to justify treatment of many children who were clearly not truly GHD (1). Thus, weak GH secretagogues, combined with an absence of sex steroid priming in prepubertal children and an unjustifiably high GH cut-off point as a marker of 'failure', led to unequivocal overdiagnosis of GHD $(1,4)$. This situation has hopefully been alleviated by the expansion of approved indications for GH; in particular, the Food and Drug Administration (FDA) approval of idiopathic short stature (ISS) and intrauterine growth retardation (IUGR) with failed catch-up growth as acceptable indications. In the case of ISS, 'short stature' was defined as -2.25 S.D. (or, approximately, the bottom $1.2 \%)$. It should be recognized, however, that this definition is totally arbitrary and could have been set just as readily at -2.0 or -3.0 s.D. The arbitrariness of any such definition is underscored by the realization that treatment cannot prevent the fact that $1.2 \%$ of children will always be below -2.25 s.D.

\section{How do we explain short stature?}

The recognition that the role of the endocrinologist in the evaluation of growth failure now goes far beyond simply determining (often incorrectly) whether or not a child is GHD, dictates an appreciation of the multigenic regulation of human growth. Since treatment of every child with a height $<-2.25$ S.D. is neither practical nor desirable, it is essential that biomarkers be identified that best predict responsiveness to specific growth-promoting therapies.

Improved understanding of the complexity of the GHIGF axis and a growing appreciation of the fundamental role of IGF-I in prenatal and postnatal growth have greatly enhanced our ability to assess the nature of proportionate short stature (1-3). It has been proposed that a critical step in the evaluation of children with short stature is assessment of the IGF status of the patient. Children, who have reduced serum IGF-I concentrations may be categorized as secondary IGF deficient (IGFD), when GH production is defective, or primary IGFD, when growth failure and low IGF-I concentrations are observed in the presence of normal or increased GH (1-3). The evaluation of rare cases of growth failure associated with mutations of the GH axis has provided us with a molecular basis for many of these patients. Secondary IGFD has thus been associated with a variety of genetic, developmental defects in pituitary development and GH secretion, while primary IGFD has been observed with molecular defects involving the GH receptor (GHR), the GHR signaling cascade, and the IGF-I gene itself. Since studies suggest that at least 25\% of children labeled as ISS have low serum IGF-I, despite apparently normal GH secretion, these rare genetic causes of primary IGFD, at least in their classical form, are likely to account for only a small percentage of patients identified as primary $\operatorname{IGFD}(2,3,5,6)$. A further explanation for such cases is necessary, and possibilities include: i) heterozygosity for specific mutations affecting the GH-IGF axis, accompanied by inadequate compensation at the level of GH production or IGF-I gene transcription and production; ii) polymorphisms of known genes of the GH-IGF axis, affecting their transcription or translation; iii) defects involving genes as yet unidentified; or iv) combinations of the factors listed above.

\section{How do we define and predict respon- siveness to growth-promoting therapy?}

The recent development of 'GH response curves' allows comparison of first year growth rates of children with GHD, Turner syndrome and ISS with data from large postmarketing studies, thereby facilitating identification of "poor responders' (7: unpublished results). It has been suggested, for example, that children whose first year growth rates fall below the -1 s.D. on such GH response curves may be identified as 'marginal responders' and would constitute candidates for re-evaluation of therapeutic options.

The administration of $\mathrm{GH}$ has traditionally been based on a body weight or body surface basis, with some modest adjustments made for underlying diagnosis and, occasionally, for puberty. This approach does not provide for the wide variation in responsiveness commonly observed, even in patients labeled as GHD (8). This problem may be especially significant in children carrying a diagnosis of ISS, with its wide heterogeneity of molecular basis. Recent studies have indicated that higher $\mathrm{GH}$ dosages, and/or GH dose titration based upon serum IGF-I levels during GH treatment, may enhance growth rates (9). The availability of IGF-I therapy, which has been recently approved by the FDA for treatment of 'severe primary IGFD', provides a potentially valuable alternative modality. The ability to determine optimal therapy at the time of diagnosis or early into treatment would clearly be of great benefit in patient management.

Initial attempts to predict the statural response to $\mathrm{GH}$ included measurement of GH-dependent serum markers, such as IGF-I, IGFBP-3 and ALS, particularly in response to short-term GH administration $(10,11)$. Thus, 'IGF 
generation tests' compared baseline and post-GH measurements of such serum markers following a 4- or 7-day course of GH therapy. While such tests are of use in identifying children with severe GH insensitivity, their ability to predict long-term $\mathrm{GH}$ response in milder cases of primary IGFD has never been adequately tested and inadequate normative data currently exist. Serial assessment of IGF-I and, perhaps, IGFBP-3 may still be recommended as a means of monitoring compliance and safety in patients receiving $\mathrm{GH}$, but further evaluation of the ability of IGF generation tests to predict long-term $\mathrm{GH}$ responsiveness is required before such tests can be recommended outside of diagnosing classical GHI and severe primary IGFD.

Various prediction models also have been developed and are of considerable interest, but those developed to date have only had a $50 \%$ correlation with one-year growth rates (12). For GHD, the best predictor (not surprisingly) has been the peak serum GH following stimulation tests, probably because this best differentiates true GHD from ISS. In the case of TS and small for gestational age (SGA), GH dosage has proven to be the best predictor. The correlation of prediction tests with one-year growth response is enhanced if short-term growth rates are entered into the equation, but this serves to limit the utility of such models in predicting growth rates at the time of initiation of therapy.

\section{Pharmacoproteomics and pharmaco- genomics and short stature}

The development of high throughput technologies for assessing proteins (proteome) or genes (genome) involved in growth holds great promise for both the diagnosis and management of growth disorders. Chung et al. (13) evaluated differential expression of serum proteins in 20 normal adults receiving $\mathrm{GH}$ and discovered a $15.1 \mathrm{kDa}$ previously unidentified GH-responsive protein. Preliminarily identified as hemoglobin $\alpha$-chain, the correlation of levels of this protein with clinical responses to $\mathrm{GH}$ remains unproven.

Nagalla and Rosenfeld (unpublished data) have evaluated protein expression patterns in patients with GHD and $\mathrm{GH}$ insensitivity (GHI) resulting from mutations of the
GHR gene using a variety of proteomic techniques, and have identified discriminatory serum protein patterns. In preliminary studies, patients with GHI or GHD could be distinguished from controls with greater than $99 \%$ confidence; GHI and GHD serum patterns could be discriminated from each other with greater than $96 \%$ confidence. These observations require large-scale confirmation, but strongly support the diagnostic value of high throughput proteomic technologies.

Genomic approaches are also showing great promise in the evaluation of patients with growth failure or abnormalities of the GH-IGF axis. Although not directly related to short stature, the exciting observation that a dominant gain-of-function mutation of the Janus kinase 2 (JAK2) gene is frequently observed in myeloproliferative disorders, especially Polycythemia vera, underscores the potential strength of this approach (14). Given that JAK2 is required for phosphorylation of the GHR and activation of STAT 5b, the critical link between the GHR and IGF-I gene activation, it appears likely that similar approaches will prove valuable in assessing genetic defects of the GH-IGF axis in short stature patients. Indeed, to date, six patients have been identified with homozygous mutations of the STAT5b gene, and resulting primary IGFD and growth failure $(15,16)$.

Dos Santos et al. (17) reported that a common polymorphism of the GHR is associated with increased responsiveness to GH. Approximately half of Western Europeans are hetero- or homozygous with respect to an allele encoding an isoform of the GHR gene that is lacking exon 3 (d3-GHR). They evaluated two cohorts of children of European descent with heights $<-2$ s.D., carrying a diagnosis of either ISS or SGA, and receiving treatment with GH. Growth rates of children carrying one or both d3-GHR alleles grew almost twice as well as children who were homozygous for the full-length isoform. Of note, however, is that baseline heights of the two groups were indistinguishable, and serum IGF-I concentrations, either before or during GH treatment, were not systematically measured. These exciting observations have been confirmed in some but not all studies, so it remains unclear at this time as to whether the d3-GHR isoform actually conveys increased GH responsiveness (18-23) (Table 1). It will require a large-scale, prospective,

Table 1 Summary of clinical investigations of the growth hormone receptor (GHR) isoform, d3-GHR.

\begin{tabular}{lccc}
\hline Author & Reference & Population & $\begin{array}{c}\text { d3-GHR correlation with GH } \\
\text { responsiveness }\end{array}$ \\
\hline Dos Santos & $(17)$ & France: ISS, SGA & + \\
Jorge & $(18)$ & Brazil: GHD & + \\
Binder & $(19)$ & Germany: SGA, TS & + \\
Pilotta & $(20)$ & Italy: GHD & - \\
Carrascosa & $(21)$ & Spain: SGA & - \\
Blum & $(22)$ & Europe: GHD & - \\
\hline
\end{tabular}

+ , Positive; -, absent; ISS, idiopathic short stature; SGA, small for gestational age; GHD, growth hormone deficient; TS, Turner syndrome. Derived from Kenth et al. (23). 
Table 2 Candidate genes for assessment of polymorphisms.

\begin{tabular}{l} 
Secondary IGFD \\
Growth hormone releasing hormone (GHRH) \\
GHRH receptor (GHRHR) \\
Growth hormone-1 (GH-1) \\
POU1-F1 \\
PROP1 \\
HESX1 \\
LHX-3 \\
LHX-4 \\
Primary IGFD \\
Growth hormone receptor (GHR) \\
JAK2 \\
STAT5b \\
STAT5a \\
IGF-I \\
IGF-II \\
IGFBPs, ALS \\
MAPK, PI3K \\
SOCS1, 2, 3 \\
IGF resistance \\
IGF-I-receptor (IGFIR) \\
Non-IGF related factors \\
SHOX \\
FGFR3 \\
NPR2 \\
\hline
\end{tabular}

well-controlled study, with appropriate assessment of proteomic and genomic markers of GH action, as well as auxological data, to settle this issue. Nevertheless, the Dos Santos study served to open the door to the potential importance of genomic and proteomic biomarkers as indicators and predictors of GH responsiveness.

\section{Future directions}

Studies are already in progress to assess both proteomic and genomic biomarkers for the evaluation and management of short stature and for the assessment of responsiveness to GH and/or IGF-I therapy. While mutations of known genes involved in the GH-IGF axis have been identified in patients with various growth disorders, attention is only beginning to be focused on polymorphisms of these genes that might result in altered expression and or function. In future studies, auxological and biochemical phenotypes will be employed to evaluate candidate genes and proteins that would correlate with secondary IGFD, primary IGFD, or IGF resistance (Table 2). Attention should be given, additionally, to non-IGF-related factors known to be active at the epiphyseal growth plate, including the genes and proteins for the Short Stature Homeobox (SHOX)-containing gene (24), fibroblast growth factor receptor (FGFR)-3 (25), the C-type natriuretic peptide receptor (NPR2) (26), and other factors yet to be identified. It is also likely that epigenetic factors, which are just beginning to be studied as contributors to growth failure, may provide important insights in the evaluation of short stature.

\section{Disclosure}

This paper forms part of a European Journal of Endocrinology supplement, supported by Ipsen. The author discloses:

Ron G Rosenfeld: only relationship with Ipsen was to receive an honorarium for talks given at a symposium. No equity position.

This article was subject to rigorous peer review before acceptance and publication.

\section{References}

1 Reiter EO \& Rosenfeld RG. Normal and aberrant growth. In Williams' Textbook of Endocrinology, edn 10, pp 1003-1114. Eds PR Larsen, HM Kronenberg, S Melmed \& KS Polonsky. Philadelphia: WB Saunders, 2003.

2 Rosenfeld RG. The molecular basis of idiopathic short stature. Growth Hormone and IGF Research 200515 S3-S5.

3 Rosenfeld RG. Molecular mechanisms of IGF-I deficiency. Hormone Research 200665 (Suppl 1) 15-20.

4 Marin G, Comene HM, Barnes KM, Blackwell BJ, Cassorla FG \& Cutler GB. The effects of estrogen priming and puberty on the GH response to standardized treadmill exercise and arginine-insulin in normal girls and boys. Journal of Clinical Endocrinology and Metabolism 199479 537-541.

5 Leschek EW, Rose SR, Yanovski JA, Troendle JF, Quigley CA, Chipman JJ, Crowe BJ, Ross JL, Cassorla FG, Blum WF, Cutler GN Jr \& Baron J. Effect of growth hormone treatment on adult height in prepubertal children with idiopathic short stature: a randomized, double-blind, placebo-controlled trial. Journal of Clinical Endocrinology and Metabolism $2004 \mathbf{8 9}$ 3140-3148.

6 Park P \& Cohen P. Insulin-like growth factor I (IGF-I) measurements in growth hormone $(\mathrm{GH})$ therapy of idiopathic short stature. Growth Hormone and IGF Research 200515 (Suppl A) S13-S20.

7 Bakker B, Frane J, Anhalt H, Lippe B \& Rosenfeld RG. Defining responsiveness to growth hormone therapy: first year growth response data from The National Cooperative Growth Study (submitted for publication).

8 Cohen P, Bright GM, Rogol AD, Kappelgaard A-M \& Rosenfeld RG. Effects of dose and gender on the growth and growth factor response to GH in GH-deficient children: implications for efficacy and safety. Journal of Clinical Endocrinology and Metabolism 2002 87 90-98.

9 Cohen P, Rogol AD, Howard CP, Bright GH, Kappelgaard A-M \& Rosenfeld RG. IGF-based dosing of GH therapy in children: a randomized controlled study. Journal of Clinical Endocrinology and Metabolism 2007 (epub).

10 Buckway CK, Guevara-Aguirre J, Pratt KL, Burren CP \& Rosenfeld RG. The IGF-I generation test revisited: a marker of GH sensitivity. Journal of Clinical Endocrinology and Metabolism $2001865176-5183$.

11 Selva KA, Buckway CK, Sexton G, Pratt KL, Tjoeng E, GuevaraAguirre J \& Rosenfeld RG. Reproducibility in patterns of IGF generation with special reference to idiopathic short stature. Hormone Research 200360 237-246.

12 Ranke MB, Lindberg A, Martin DD, Bakker B, Wilton P, Albertsson-Wikland K, Cowell CT, Price DA \& Reiter EO. The mathematical model for total pubertal growth in idiopathic growth hormone $(\mathrm{GH})$ deficiency suggests a moderate role of $\mathrm{GH}$ dose. Journal of Clinical Endocrinology and Metabolism $2003 \mathbf{8 8}$ $125-131$. 
13 Chung L, Clifford D, Buckley M \& Baxter C. Novel biomarkers of human growth hormone action from serum proteomic profiling using protein chip mass spectrometry. Jorunal of Clinical Endocrinology and Metabolism $200691671-677$.

14 Scott LM, Tong W, Levine RL, Scott MA, Beer PA, Stratton MR, Futreal A, Erber WN, McMullin MF, Harrison CN, Warren AJ, Gilliland DG, Lodish HF \& Green AR. JAK2 exon 12 mutations in polycythemia vera and idiopathic erythrocytosis. New England Journal of Medicine 2007356 459-468.

15 Kofoed EM, Hwa V, Little B, Woods KA, Buckway CK, Tsubaki J, Pratt KL, Bezrodnik L, Jasper H, Tepper A, Heinrich JJ \& Rosenfeld RG. Growth hormone insensitivity associated with a STAT5b mutation. New England Journal of Medicine $2003 \mathbf{3 4 9}$ 1139-1147.

16 Rosenfeld RG, Belgorsky A, Camacho-Hubner C, Savage MO, Wit JM \& Hwa V. Defects in growth hormone receptor signaling. Trends in Endocrinology and Metabolism 200718 134-141.

17 Dos Santos C, Essioux L, Teinturier C, Tauber M, Goffin V \& Bougneres P. A common polymorphism of the growth hormone receptor is associated with increased responsiveness to growth hormone. Nature Genetics 200436 720-724.

18 Jorge AA, Marchisotti FG, Montenegro LR, Carvalho LR, Mendonca BB \& Arnhold IJ. Growth hormone (GH) pharmacogenetics: indluence of $\mathrm{GH}$ receptor exon 3 retention or deletion on first-year growth response and final height in patients with severe GH deficiency. Journal of Clinical Endocrinology and Metabolism 200691 1076-1080.

19 Binder G, Baur F, Schweizer R \& Ranke MB. The d3- growth hormone $(\mathrm{GH})$ receptor polymorphism is associated with increased responsiveness to GH in Turner syndrome and short small-forgestational-age children. Journal of Clinical Endocrinology and Metabolism 200691 659-664.

20 Pilotta A, Mella P, Filsetti M, Felappi B, Prandi E, Parrinello G, Notarangelo LD \& Buzi F. Common polymorphisms of the growth hormone $(\mathrm{GH})$ do not correlate with the growth response to exogenous recombinant human $\mathrm{GH}$ in $\mathrm{GH}$-deficient children. Journal of Clinical Endocrinology and Metabolism $2006 \mathbf{9 1}$ 1178-1180.
21 Carrascosa A, Esteban C, Espadero R, Fernandez-Cancio M, Andaluz P, Clemente MA, Audi L, Wollman H, Fryklund L, Parodi L \& the Spanish Study Group. The d3- growth hormone receptor polymorphism does not influence the effect of GH treatment ( $66 \mu \mathrm{g} / \mathrm{k}$ per day) or the spontaneous growth in short non-GH-deficient small-for-gestational-age children: results from a two-year controlled prospective study in 179 Spanish patients. Journal of Clinical Endocrinology and Metabolism $2006 \mathbf{9 1}$ 3281-3286.

22 Blum W, Machinis K, Shavrikova E, Keller A, Stobbe H, Pfaffle R \& Amselem S. The growth response to growth hormone (GH) treatment in children with isolated GH deficiency is independent of the presence of the exon-3-minus isoform of the $\mathrm{GH}$ receptor. Journal of Clinical Endocrinology and Metabolism $2006 \mathbf{9 1}$ 4171-4174.

23 Kenth G, Shao Z, Cole DE \& Goodyer CG. Relationship of the human growth hormone receptor exon 3 genotype with final adult height and bone mineral density. Journal of Clinical Endocrinology and Metabolism 200792 725-728.

24 Rappold G, Blum WF, Shavrikova EP, Crowe BJ, Roeth R, Quigley CA, Ross JL \& Niesler B. Genotypes and phenotypes in children with short stature: clinical indicators of SHOX haploinsufficiency. Journal of Medical Genetics $2007 \mathbf{4 4}$ 306-313.

25 Vajo Z, Francomano CA \& Wilkin DJ. The molecular and genetic basis of fibroblast growth factor receptor 3 disorders: the achondroplasia family of skeletal dysplasias, Muenke craniosynostosis, and Crouzon syndrome with acanthosis nigricans. Endocrine Reviews 200021 23-39.

26 Olney RC, Bukulmez H, Bartels CF, Prickett TC, Espiner EA, Potter LR \& Warman ML. Heterozygous mutations in natriuretic peptide receptor-B (NPR2) are associated with short stature. Journal of Clinical Endocrinology and Metabolism $2006 \mathbf{9 1}$ 1218-1219.

Received 22 March 2007

Accepted 23 April 2007 